\title{
A Study of Golden Rule for Establishment of a National Nuclear Protection System
}

\author{
Kim Hakmin \\ Center for Military Analysis and Planning, Korea Institute of Defense Analysis, Seoul, Republic of Korea \\ Email address: \\ minmo5@kida.re.kr,minmo5@hanmail.net

\section{To cite this article:} \\ Kim Hakmin. A Study of Golden Rule for Establishment of a National Nuclear Protection System. Journal of Public Policy and \\ Administration. Vol. 3, No. 2, 2019, pp. 49-60. doi: 10.11648/j.jppa.20190302.12
}

Received: July 27, 2019; Accepted: August 28, 2019; Published: September 11, 2019

\begin{abstract}
The escalation of NK's nuclear and missile capabilities has been caused home to us the urgency and necessity of building a nuclear protection system in the national level. The realistic necessity, importance, and justification for the establishment of the nuclear protection system to ensure the lives and safety of the people and to minimize damage are increasing. Accordingly, the purpose of this study is to establish a national nuclear protection system against the growing threats of NK's nuclear weapons. This study THIRA technique in FEMA of the U.S. and a likely nuclear damage scenario, and TC, TCL and each TCL Level has proposed reasonable measures to ensure survival and minimize damage. It also proposes ways to overcome limited resources and to use the developed military capability, thereby making it possible to save and focus resources. This is to decide on the priorities and direction at which they will be presented in the future national level.
\end{abstract}

Keywords: TC (Target Capability), TCL (Target Capability List), Prevention, Preparedness, Response, Recovery

\section{Introduction}

North Korea has made nuclear threats by conducting the sixth nuclear tests and a lots of missile tests, and has continued to make threatening, provocative and belligerent threats against the U.S. and South Korea. Nevertheless, Korea didn't have a lot of discussions and preparations to establish the nuclear defense system. Considering North Korea's nuclear threat and increased uncertainty of nation security, the discussions and preparations to strengthen the nation's nuclear defense capability are crucial. In response to North Korea's nuclear and missile threats, the ROK-U.S. alliance has developed a Tailored Deterrence Strategy and Four D (Detect, Disrupt, Defense, Destroy) operational concepts, and a Three K (Kill Chain, Korea Air and Missile Defense, Korea Massive Punishment and Retaliation) system of South Korea, but the establishment of a nuclear defense system has not been advanced. Therefore, this study was put forward according to the importance, necessity and urgency of building a nuclear protection system, and the purpose of the study is to propose the Golden Rule for the early establishment of a national nuclear protection system to the guarantee the life and safety of the people and to minimize the damage. This is to identify realistic and practical countermeasures to minimize damage and ensure viability through limited budgets and shortest-term effective deployment. If a national nuclear protection system is early established, it could be means of increasing nuclear deterrent force.

In order to establish a national nuclear protection system, the target capability and target capability list should be identified first, and the demanded capability, development direction, and deployment priority should be identified by the identified TCL (target capability list). In this study, we applied the threat identification and risk assessment (THIRA) technique applied by the Federal Emergency Management Agency (FEMA) to identify TCs (target capability) and TCLs (target capability list). Existing studies are mainly studies on expected damage, survival and evacuation [1-3], disaster management [4-10] and the direction for the establishment of evacuation facilities [11-13] but have been presented. Therefore, this study, through the nuclear explosion damage scenarios, identifies the TC. TCL for nuclear protection and seeks to derive the Golden Rule for building a national nuclear protection system, and is expected to help in decision making and policy making for the establishment of a nuclear protection system in the future. 


\section{The Expected Damage of Nuclear Bombs Explosion}

\subsection{A Yield and Effectiveness of Nuclear Bombs Explosion}

When twenty kiloton of a nuclear bomb explodes, there are initial and delayed effects. Initial effects are effects that occur within one minute of a nuclear explosion, with fifty-five percent storm, thirty-five percent thermal radiation, four-teen percent radiation with fallout, and one percent EMP. Radiation consists of four percent initial ionizing radiation emitted within one minute of explosion and ten percent of residual radiation contained in radioactive fallout, and EMP (Electronic Pulse, Electromagnetic Pulse) disables electrical and electronic devices. The delayed effect consists of fallout and sensitivity radiation, and radiation damage is affected by distance, time, and shielding.
The Yield of a nuclear bomb is mainly expressed as TNT power. If a twenty kiloton nuclear bomb explodes in the air, as shown in Table 1, most buildings within a two km radius can be destroyed, and a person can be mortally burned. The estimation of the victims of the initial effects of the nuclear bomb explosion is that everyone within the five psi explosion pressure line from a ground zero can be dying [14]. The effects of a nuclear explosion are affected by Yield and HOB (high altitude), and the initial effects that is occurred in a second after a nuclear explosion are reduced by the shielding. The sensitive radiation and the fallout that is occurred the delayed effects spreads along a direction of the wind, but will weaken in two weeks, and if a direct damage is prevented by using a shelter or a tool that can protect the body, the damage through fallout can be almost avoided. Radiation is not contagious and a physical damage will be reduced two point five kilometer from the ground zero [15].

Table 1. Radius of nuclear weapons effect (structural effects).

\begin{tabular}{|c|c|c|c|c|c|}
\hline \multirow[b]{2}{*}{ Effect (radius, km } & & \multicolumn{4}{|c|}{ Nuclear Explosion scale /HOB } \\
\hline & & $\begin{array}{l}\text { 1kiloton } \\
/ 0.2 \mathrm{~km} \\
\end{array}$ & $\begin{array}{l}\text { 20kiloton } \\
\text { /0.54km } \\
\end{array}$ & $\mathbf{1 M t} / 2 \mathbf{k m}$ & $20 \mathrm{Mt} / 5.4 \mathrm{~km}$ \\
\hline \multirow{4}{*}{ blast effect } & city complete destruction $(20 \mathrm{psi} / 140 \mathrm{kPa})$ & 0.2 & 0.6 & 2.4 & 6.4 \\
\hline & most of building destruction $(5 \mathrm{psi} / 34 \mathrm{kPa})$ & 0.6 & 1.7 & 6.2 & 17 \\
\hline & partly building destruction $(1 \mathrm{psi} / 6.9 \mathrm{kPa})$ & 1.7 & 4.7 & 17 & 47 \\
\hline & drived vehicle train wrecks destruction $\left(0.63 \mathrm{kp} / \mathrm{cm}^{2}=62 \mathrm{kPa}\right)$ & $\approx 0.4$ & $\approx 1.0$ & $\approx 4$ & $\approx 10$ \\
\hline \multirow{3}{*}{ thermal radiation } & third degree burn & 0.6 & 2.5 & 12 & 38 \\
\hline & second degree burn & 0.8 & 3.2 & 15 & 44 \\
\hline & first degree burn & 1.1 & 4.2 & 19 & 53 \\
\hline \multirow{2}{*}{ radiation } & fatal exposure dose & 0.8 & 1.4 & 2.3 & 4.7 \\
\hline & raised up radiation disease exposure dose & 1.2 & 1.8 & 2.9 & 5.4 \\
\hline
\end{tabular}

* Source: Atomic Energy Control Technology Institute, 'KINAC/TR-044 Technology Report (2010), p.5.

\subsection{A Case Study on the Damage by Nuclear Explosions: Focused on Hiroshima and Nagasaki Case}

A people had been killed 160,000 people by a fifteen kilogram uranium atomic bomb exploded 500 meter above sea level in Hiroshima on August 6, 1945. (thirty-eight percent as of December, 1945). Since then, people had been killed 70,000 people by a twenty kilogram plutonium atomic bomb exploded 600 meter above sea level in Nagasaki on August 9 (twenty-six percent as of 1997). However, the mortality rate is fifty-seven percent including 352,550 deaths (as reported to the United Nations as of March 31, 1990) estimated under Japan's Atomic Bomb Medical Support Act [16]. In Hiroshima, eighty-seven percent of people within one kilometer were killed and All of the wooden buildings within two point five kilometer from the ground zero were burned. Deaths from direct burns, such as deaths of ninetyfive percent of the population within 800 meter from the ground zero, twenty percent from radiation exposure, and fifty percent from injuries caused by collapsed buildings and flying debris $[17,18]$.

In other words, exposed personnel within a two kilometer radius of the ground zero within one minute of the nuclear explosion were either killed or injured at the site, and secondary damages occurred between large-scale fire and radiation exposure and emergency and relief activities. Additional deaths of people exposed to more than lethal doses of radiation after the days of nuclear explosions, and psychological panic spread caused by the full-scale impact of atomic disease [18]. In other words, it was minor damage other than the windows outside five kilometer, and damage to modern buildings within five kilometer was lighter than expected.

The U.S. DTRA (Department of Defense Threat Reduction) estimated that six point three million people would suffer from the results of its 2004 nuclear bomb M/S. If a 100 kiloton nuclear bomb is dropped over Seoul without warning, 380,000 people will die, 230,000 will be seriously injured, about three million will die due to radioactive fallout, and about two million will be seriously injured. According to Dr. Matthew G. McKenzie of the Natural Resources Defense Council (NRDC) and Thomas Cochran of the U.S. Department of Defense released in 2004, between fifty-teen and twenty kiloton of bombs exploded over Yongsan, Seoul, 62,000 people can be killed, and 84,000 people can be killed $[19,20]$.

These studies show that the effects of fallout, which is a delay, are much larger than the damage caused by the initial 
effects, and that the damage from the ground explosion is larger than the air explosion. The reason is that ground explosions cause a large amount of fallout, but air explosions are relatively low. Fallout damage can be reduced almost by evacuating for a certain period of time [18].

\section{THIRA and the Nuclear Bombs Explosion Scenario}

\subsection{Development and Application of THIRA}

The purpose of the application of the Threat Hazard Identification and Risk Assessment Guide (THIRA) is to present an effective and efficient response through the identification of the TC (target capability) and TCL (target capability list) required by analyzing the damage assessment and impact of nuclear explosions through a reasonable and efficient assessment and analysis. THIRA describes a standard procedure to identify threats and risk factors when setting the target capacity of each key function as identified by the Department of Homeland Security's National Priorities Goal (DHS). THIRA procedure is to identify and assess risks associated with homeland and state security hazards in the
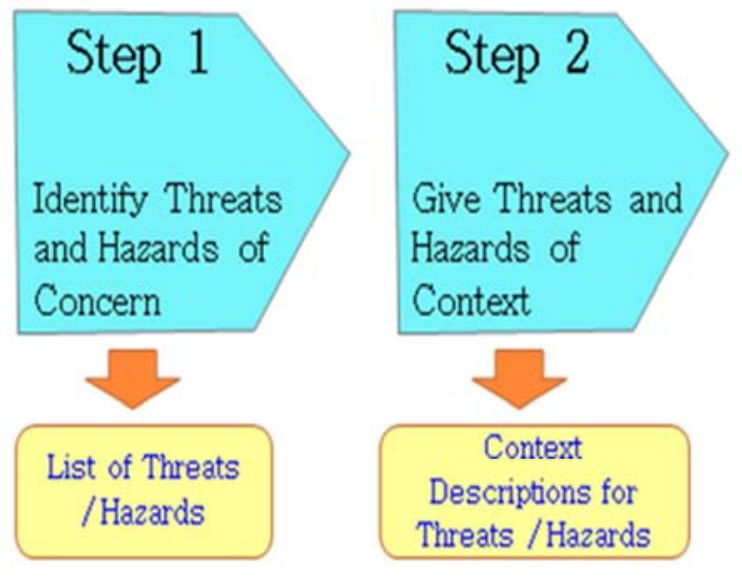

Figure 1. THIRA Development and Step-by-Step Application. established. $[4,21]$

United States. It is a useful procedure that can be applied to the direction in which the nuclear protection system is

The first phase of THIRA (threats and risk factors identification) developed a scenario of possible nuclear explosion damage as part of identifying and listing North Korean nuclear threats and risk factors. This provides useful data for identifying preparedness and response tasks. The scenarios for potential damage from the nuclear explosion were supplemented by the cases of damage from Hiroshima and Nagasaki and through expert discussions in order to enhance completeness and reliability. Phase 2 of THIRA (threats and hazardous situations) is the process of identifying and deriving the TC and TCLs required by determining the likely damage in a nuclear explosion and identifying the preparedness and response tasks, referring to the UTL, TC, and TCLs of the U.S. FEMA. In phase third of THIRA (Building Objective Capabilities), the current capability by TCL was evaluated quantitatively and qualitatively. Phase fourth of THIRA (applications of results) presented the identified TCL specific requirements, direction of development and priorities for the establishment of a national nuclear protection system [21].

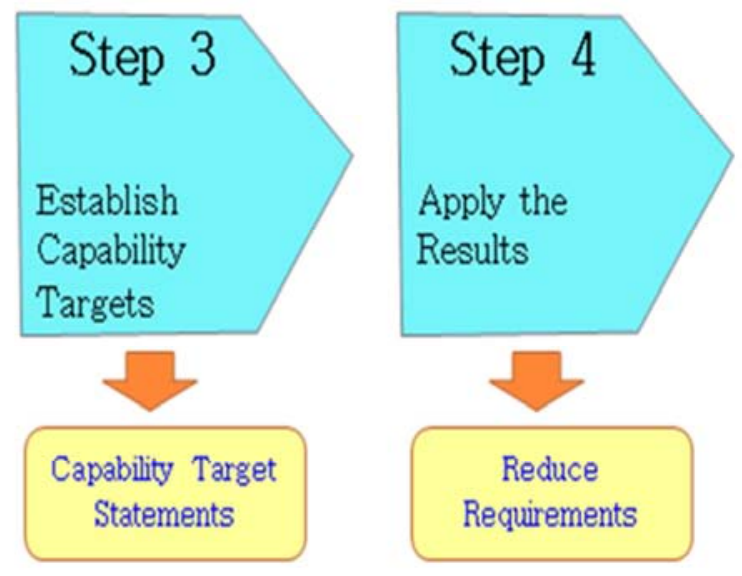

*source: Homeland Security. (2013). Threat and Hazard Identification and Risk Assessment Guide: Comprehensive Preparedness Guide (CPG) Second Edition 201 was reconstructed.

\subsection{Stage 1 THIRA (Threat and Hazard Identification): Nuclear Explosion Damage Scenario}

In order to effectively respond to a nuclear explosion, it is necessary to clarify the scenario of possible damage by time and distance based on the effects and yields of a nuclear explosion. It is important to identify ways to prevent, mitigate, and minimize the effects of nuclear explosions, and early to maintain and recover national functions. This is because the scenario of nuclear explosion damage can help identify TC and TCL to establish an effective and efficient national protection system. Because TC and TCL are identifying tasks that must be prepared in advance and those that must be addressed afterwards [21]. The scenario was prepared with reference to Chapter Two. If North Korea launches a nuclear missile, South Korea should promptly issue an alert and radio signal considering the flight time, and force all residents who failed to evacuate through real-time alerts to the anticipated area of nuclear explosion to evacuate immediately. At that time, all citizens of the expected offensive areas, including civil defense personnel, must evacuate to underground evacuation facilities, and there must be no people who have not yet been evacuated. Therefore, it is necessary to distinguish between nationwide alarm signals and tailored alarm signals for anticipated explosion sites.

In the event of a nuclear explosion, all personnel on the ground within a radius of two kilometer from the ground zero can be killed in the field and buildings can be collapsed, and 
electric power and telecommunication networks can be paralyzed locally (assuming a nuclear explosion of twenty kiloton class). And small and large fire can be occurred in the damaged area. All of that will occur in one minute after nuclear explosion. From one minute after the nuclear explosion to two days, the second damage will takes place seriously, and it is divided into two stages. First of all, fallout damage within a radius of five kilometer from one minute to two hours after the nuclear explosion will occur seriously, collapse of all nearby buildings, and fire of small and large scale. And It will be caused secondary damage by impact and debris, including broken windows flying in all directions. In particular, the explosion of gas stations or city gas will cause a massive fire. Collapse of national infrastructure, such as major roads, railways, electric power and telecommunications, will cause uncontrollable confusion and panic. Immediate emergency, rescue and relief will be limited by lethal residual radiation within a radius of two kilometer from the ground zero.

Exposure from fallout continues from two hours after the nuclear explosion to two days, and breathing will be difficult due to various fires within a radius of five kilometer. Normal assistance such as emergency, rescue, relief and medical aid will be limited, and damage will be increased due to the lack of emergency and precision decontamination facilities. If a field command headquarters by local governments and an integrated support headquarters by the government are established, more systematic responses can be made. From two days after the nuclear explosion to the fifteen days, casualties will be caused only by the fallout damage, and most of the fires should be noted for situations in which they are suppressed.

\section{Golden Rule and TC/TCL for Nuclear Protection}

\subsection{Framework}

The purpose of building a national nuclear protection system is to ensure the people's lives and safety through proactive preparedness and response, and the expected damage prevent, mitigate, maintain, and the paralyzed state functions recover early. Figure 2 The Nuclear Protection Framework shows the government's support to ensure the military's continuing war, the role of the military to minimize damage to the people, and the international community's support for parts beyond national capabilities, and the interconnections of legal and institutional systems to achieve this. The government will take leading actions to prevent, mitigate and maintain damage, ensuring that the military carries out war, while the Defense Ministry and the military should actively intervene within the scope of their capabilities to minimize the damage [22]. The support of UN, FCM of the U.S. (Foreign Consequence Management), IGO (International Intergovernmental Organization) and NGO (Nongovernment Organization) should be consolidated because of the lack of national self-capability for response.

\section{Prevention- Preparedness - Response- Recovery}

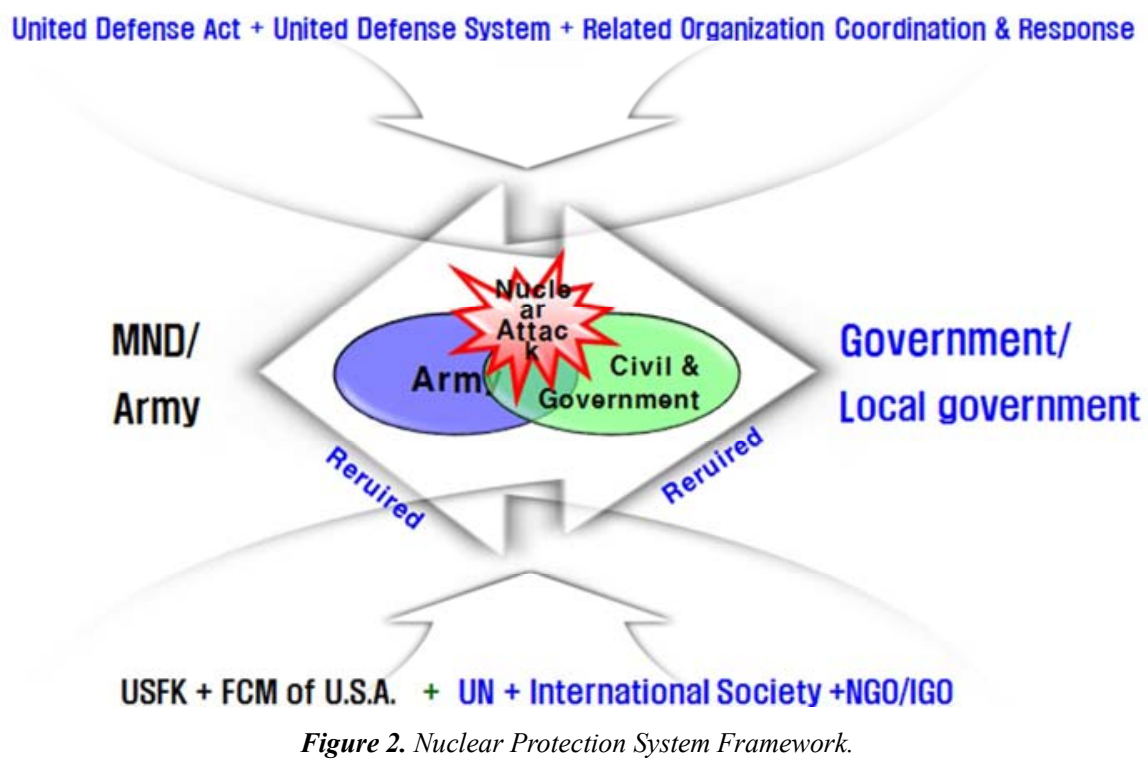

* Source: Kim Hakmin, "Fourth North Korean nuclear test and our preparation and response direction," Defense Policy Research Vol.32, Volume II (Korea Institute for Defense Analyses, 2016), p. 45.

\subsection{Stage 2 THIRA (Threats, Hazards)-TC and TCL}

TC for nuclear protection of the national level is to "ensure the lives and safety of the people, minimize potential damage, and secure the ability to be equipped for early national functioning maintenance and recover of the original state." TCLs to achieve TCs identified twelve lists as shown in Figure third by referring to expert discussions, US FEMA's 
TCLs, Government's Disaster and Safety Management TCLs, and twelve TCLs were classified into six Categories. The six Categories were divided into common areas (legal and institutional aspects-crisis management systems-national education and training-communication information distribution), pre-preparation (evacuation facilities, evacuation systems), and post-response areas (response, rehabilitation and recovery). This contributes to do continuously war and minimize expected damage, the goal for establishment of nuclear protection system, maintenance of national functions and recover of its original state.

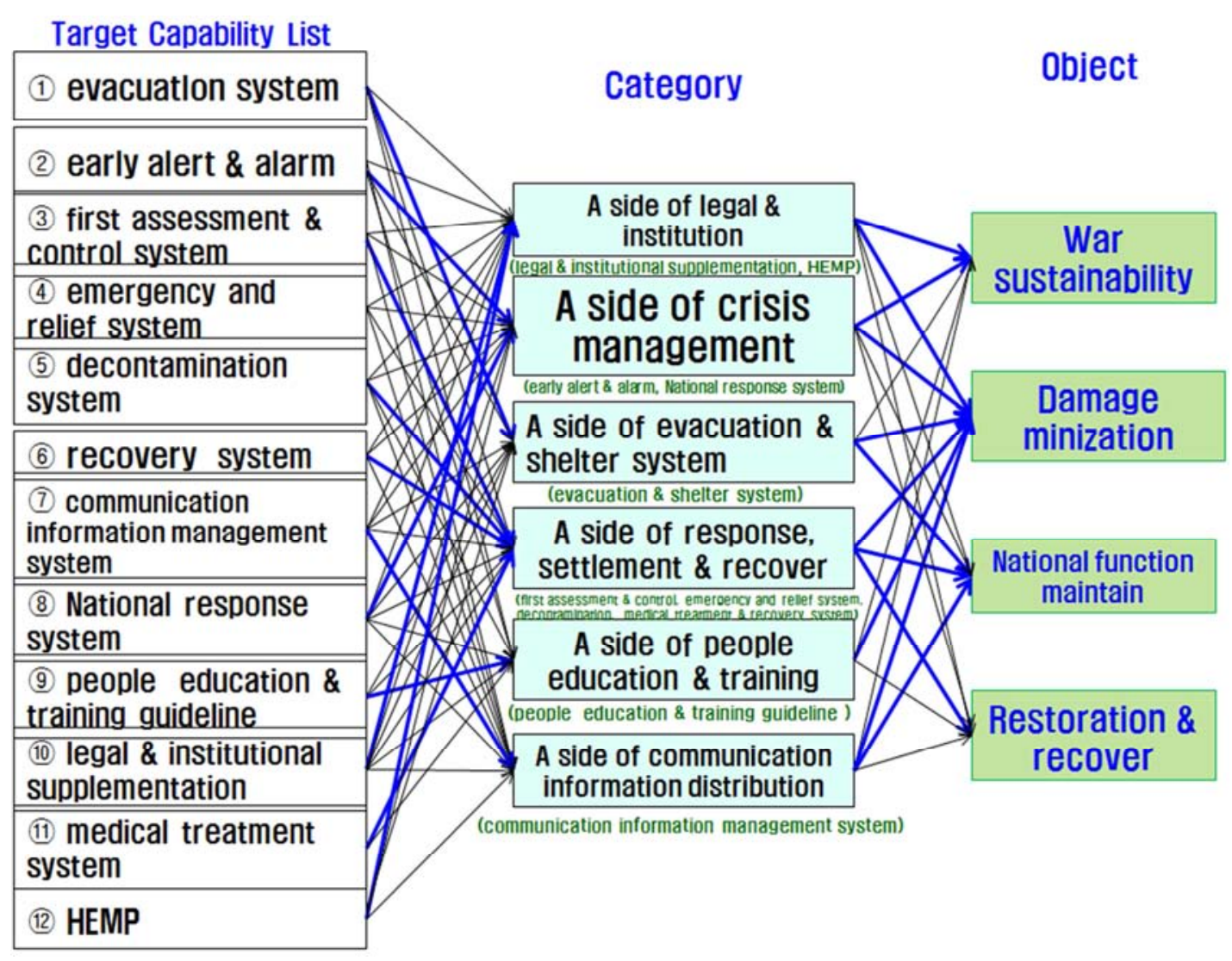

Figure 3. Relationship of Goal-Category-TCL for establishment of nuclear protection system of National level.

\subsection{Stage 3 THIRA (TC)-Golden Rule for Establishment of National Nuclear Protection System}

The country's nuclear protection goal should be to rationalize the level and conditions of damage minimization rather than damage "zero" through applying the ALARA and ALARP principles. That is, the ALARA principle to reduce risk as low as possible to the extent that it can be reasonably reduced and the ALARP principle to minimize damage to the extent reasonably achievable. ${ }^{1}$ This will result in the suggested TCL-specific target levels and priorities being the Golden Rule to optimize the nuclear protection system.

The atomic bomb mortality rates in Hiroshima and Nagasaki were affected by distance and time from the ground zero, as shown in Table one and Figure four ALARA [16]. The result enables qualitative and quantitative reasoning that proactive preparedness and efficient response, differentiated by time and distance, can greatly reduce damage. In other words, it is estimated that a reduction of 96.5 percent of mortality within

\footnotetext{
1 ALARA (As Low As Reasonably Achievable); ALARP (As Low As Reasonably Practicable).
}

500 meter from the ground zero could be possible in stages up to sixty percent and up to twenty percent depending on the level of pre-contamination and contrast and response to the supplemented underground shelter. Applying the same target level ratio, 51.6 percent of deaths within one to one point five kilometer from the ground zero can be reduced step by step to a minimum of nineteen percent and a maximum of six point four percent. And a two point seven percent mortality rate within two point five to three kilometer from the ground zero can be reduced to a minimum of two point six percent and a maximum of one point two percent by applying the same target level ratio. In addition, one point one percent of deaths within four to five kilometer from the ground zero could be reduced to a minimum of zero point seven percent and up to zero point two percent.

In conclusion, the mortality rate we want to reduce is a nuclear protection target for our preparedness and response measures. In other words, the mortality rate within zero point five kilometer from the ground zero is twenty percent, six point four percent within from zero point five to one point five kilometer, one point two percent within from one point five to three kilometer and one point two percent within from 
three to five kilometer. This is because, as mentioned in Chapter Two, damage can be 'Zero' if it is evacuated to an underground evacuation facility within a radius of two to five kilometer from a violent location. In addition, if the affected area is evacuated to a supplemented underground shelter within a two kilometer radius, the potential damage could be reduced by up to fifty percent. The protection target reflected the completeness and determination of the protection system we intend to build. It will prevent ninety percent of fallout damage through preparedness and reduce initial damage (storms, heat radiation, radiation exposure) by more than fifty percent through evacuation to underground evacuation facilities. It will also further reduce and mitigate the damage through systematic response by the civil defense system. According to the analysis of war veterans from the U.S. and Britain during World War II, Germany and Japan are reported to have reduced damage caused by their superior civil air defense posture (alert ant alarm warning, firefighting activities, etc.) by thirty to fifty percent [21].

Table 2. Death rate and died civilian by distance in Hiroshima.

\begin{tabular}{|c|c|c|c|c|c|c|c|c|c|}
\hline Classification (km) & Total & $0 \sim 0.5$ & $0.5 \sim 1$ & $1 \sim 1.5$ & 1.5 2 & $2 \sim 2.5$ & 2.5 3 & $3 \sim 4$ & $4 \sim 5 \mathrm{~km}$ \\
\hline Resident Population & 420,000 & \multicolumn{4}{|c|}{200,000} & \multicolumn{4}{|c|}{220,000} \\
\hline Fatality & 140,000 & \multicolumn{4}{|c|}{$125,000(62.5 \%)$} & \multicolumn{4}{|c|}{$15,000(7 \%)$} \\
\hline Fatality Rate (\%) & 33 & 96.5 & 83.0 & 51.6 & 21.9 & 4.9 & 2.7 & 2.5 & 1.1 \\
\hline
\end{tabular}

Rate of deaths due to the atomic bom

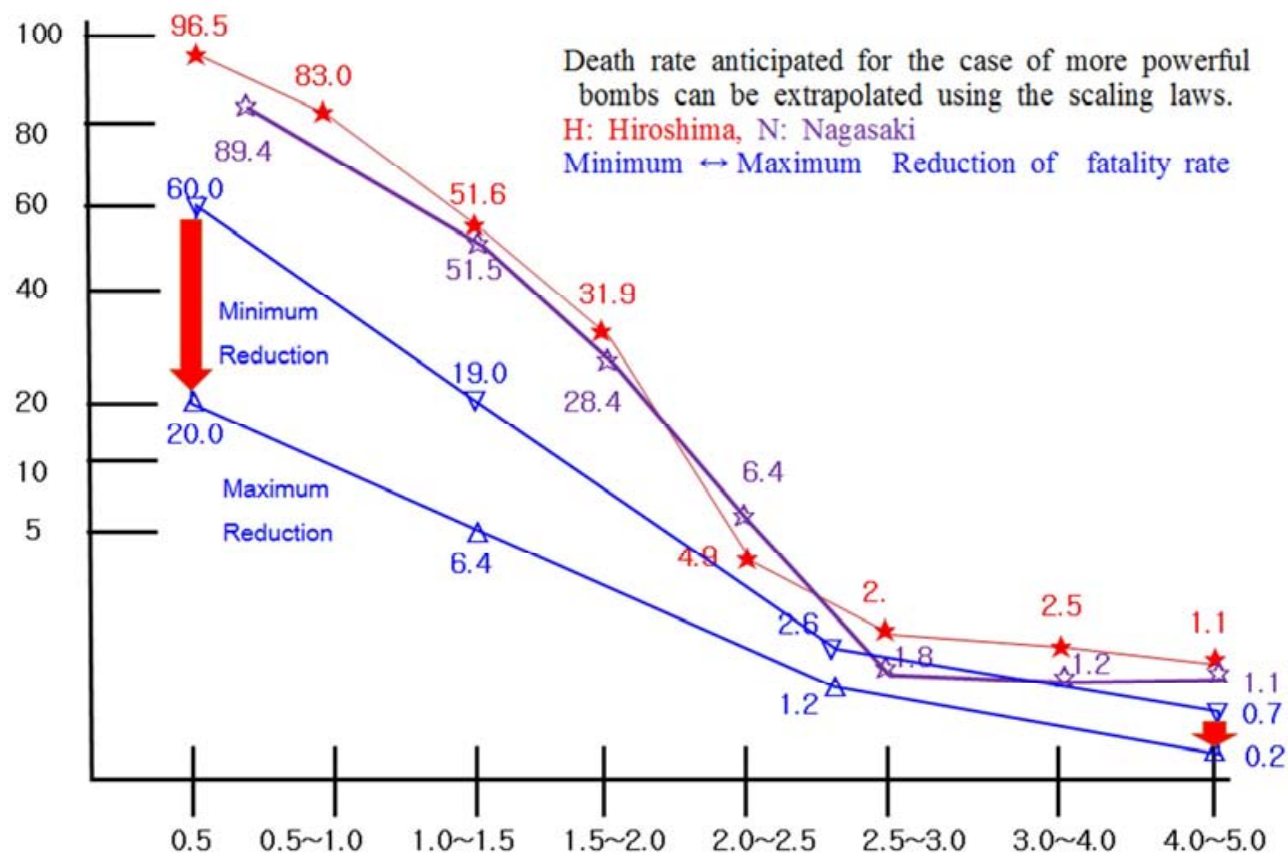

\section{Distance from Hypocenter $(\mathrm{km})$}

Figure 4. Death rate and reduction plan by Atomic Bomb in Hiroshima and Nagasaki (Estimate)

*source: Japan Foreign Affairs. (2014). "Research Study on Impacts of the use of Naval Nuclear Weapons in Varies Aspects" Commissioned by the Ministry of Japan Foreign Affairs. p. 16. restructured.

\subsection{Stage 4 THIRA (Apply the Result): Golden Rule for Nation Nuclear Protection Goal}

Golden Rule for establishment of the Nuclear Protection System is intended to present a reasonable national defense system for reducing the expected initial and delayed effects of a nuclear explosion to Maximum-Minimum to achieve the above-mentioned level. The six categories and TCL's role to minimize nuclear explosion damage are shown in Figure 5. This shows the relationship between preparedness, response and shape. Underground evacuation facilities will reduce much of the initial damage and fallout damage, and the establishment of an evacuation system (dispersion and evacuate) will enhance the effects to reduce a nuclear explosion damage. The national nuclear crisis management system (timely alerting and dissemination, control tower, etc.) greatly contributes to prevent, mitigate and maintain nuclear explosion damage. Continued training and education will be the less reduction nuclear explosion damage and do a decisive role. Response (timely emergency and relief, fire suppression, etc.) is critical point to prevent and mitigate the spread of damage. In addition, supplementation of legal and institutional level and the communication information 
management system through real-time command control will play an important role to minimize damage. In conclusion, Golden Rule for establishment of the Nuclear Protection
System is firstly to concentrate on preparedness, next to make additional efforts in a shape activity rather than response activity.

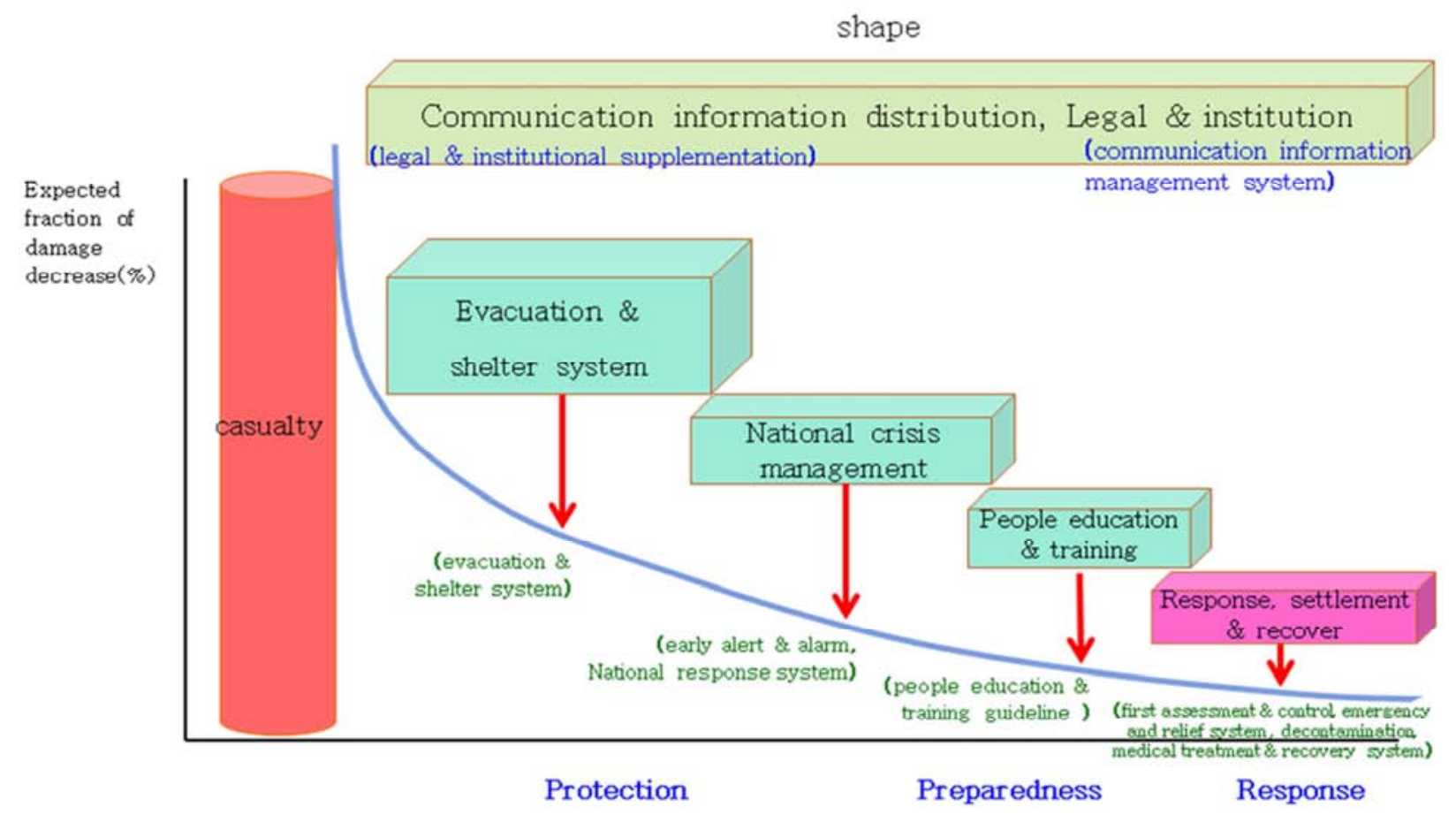

Figure 5. Direction of TC and TCL to minimize nuclear explosion damage.

\section{Direction for Establishment of National Nuclear Protection System}

\subsection{Supplementation of Legal and Institutional Level}

The establishment of the national nuclear protection system requires integrated laws and guidelines to prepare against the occurrence of nuclear explosion damage, and the maintenance of interconnection and supplementation of "Civilian Defense Act" as the top law in the war. Therefore the government structure should be developed so that it can take the initiative by the Control Tower. In addition, it is necessary to supplement the system so that the combined capabilities of the civilian, government and military systems can be improved and the pan-government and civilianmilitary efforts can be integrated. The U.S. NRF was established in 2008 (HSPD-5) and all related vertical and horizontal documents are structured. All Hazards Approach (Disaster Management System) aims for mutual cooperation with NRF (National Disaster Response System) and NIMS (National Accident Management System), central and local governments, NGOs, and private organizations, and NIMS provides a standardized system for disaster management and response activities of the ICS (On-site Command System). DHS (Ministry of National Security) is preparing for all risks at home and abroad, while FEMA (Federal Emergency Management Agency) is in charge of disaster management and NRF programs. State or local government systematically responds to EOO operation, EOC installation, ICS etc [23].
As such, the U.S. has interlinked legal and institutional integration to enable vertical and horizontal role classification of all relevant agencies within the NIMS. Israel's HFC (Rear Command, 1992) is an independent command under the command of the General Staff, linking defense and disaster preparedness, and is integrated into civilian defense of priority military and emergency preparedness that combined military operations in 2014.

Thus, the "Civilian Defense Act," the "Integrated Defense Act," and "War relations Act," which are supplemented, should be specified the structure of the organization, such as the national integration response system and control tower, and the functions and roles of each organization. In addition, a national integration response system should be established so that local government heads can conduct on-site instruction and integrated supporting of government. The "Integrated Defense Act" should reflect and supplement the military's role, including preemptive preparedness and response, integration of civil and military efforts, unity of the command system. Revisions to relevant laws, such as legal and institutional supplementation, should be made first, but require a lot of time. It is necessary to consider the urgency to prevent any delays in the required time frame and to review the direction of development and supplementation of the presidential guidelines (rules) for example as in the United States.

\subsection{Establishes and Implements a National Nuclear Crisis Management System}

The U.S. Department of Homeland Security (DHS) is 
prepared against all risks at home and abroad, while the NIMS (National Accident Management System) uses an integrated structure and systematic ways and a comprehensive approaching of the national level against all potential accidents, risk scenarios. The U.S. has established vertical systems of nation level such as HSPD-5, HSPD-7/8 and PDD-39/6235 to be marked a role and functions of preparedness, communication information, resources, command management, and continued maintenance and management by including ICS, MACS, and public communication $^{1}$

The National Nuclear Crisis Management Agency needs to transform the crisis management paradigm and develop concepts, including signs of a nuclear attack, and preemptive, active and aggressive responses to prevent and minimize damage through alarms and radio waves, depending on the permanence of time and the infinite nature of measures, and the severity of responsibility. In other words, the Nuclear Crisis Management should identify preemptive preparedness and response measures for ensuring survival and preventing, mitigating and maintaining damage, and should coordinate and link various measures, including R. O. K-U.S. unified joint crisis management and decision-making steps, through SOP. They include the system of early alert-warning, evacuation to underground evacuation facilities, vertical and horizontal command control, protection of government facilities, and national crisis management plans. The establishment of an intelligent and smart integrated alert system should allow for transmission within 2minutes without alarm blind spots, and ensure continuity of situation propagation for control of damage, thus preventing damage from spreading. The role of control tower is important in order to prevent, mitigate and maintain nuclear explosion damage to response through an organized and systematic ways.

\subsection{Establishes and Implements of Evacuation Facility and System}

The time required to evacuate to an underground evacuation facility must be within 5 minutes considering the missile flight time from North Korea's missile launch area, but the majority of facilities currently take between 11 and 30minutes, and the difference between the resident and floating population are not considered, so we should be reviewed all of that.

Switzerland reflected the obligation for underground defense in new buildings and areas with more than 1,000 residents (1950s) and fully equipped the civil defense system with the Federal Civil Defense Act (March 23, 1962.) and the

\footnotetext{
1 MACS: Multi-agency coordination system, HSPD-5: National Security Presidential Order No.5, government-civilian-NGO collaboration guarantee, HSPD-7: Identification of National Core Infrastructure and Prioritization, HSPD8: Establishment of national preparedness system, NRF: National Response Framework, policy-operation guidance-structure-mechanism-guideline/procedure, PDD-39 / PDD-6235: Basis for the execution of policies/plan related to presidential orders, chemical and biological situations, major disasters, and emergencies.
}

Civil Defense Ordinance issued (1964s). The government if people want to build new building supports 30percent of the construction of underground rooms and reviews them in advance by the Civil Defense Commission. The air-raid shelter was prepared to accommodate 350 patients, to allow for 18 months to be settled, and 100 percent of the people, including relief, medical, communications, and defense industrial facilities, were supplemented from 1990 to concurrently evacuate.

Israel distinguishes cities from rural areas, allowing everyone to evacuate. Urban shelters are divided into exterior (shelter) and interior (building), and rural areas are used as shelters by building underground facilities.

The establishment of underground evacuation facilities and evacuation systems is the most important national nuclear protection system to ensure the lives and safety of the people and minimize damage against nuclear explosion damage. The underground evacuation facility should have a nuclear defense facility which considers EMP to the government facilities and a civil defense evacuation facility to ensure the safety and life of the people, but needs to differentiate the criteria based on threat priorities by considering astronomical budgets.

A shelter shall be located a fallout shelter to be able going within 5minutes (about 250 meters) after alert and warning for nuclear explosion damage, and the required space for each resident and floating population is planned and secured.

Evacuation systems include the concept of evacuation, the required space of evacuation facilities, a required time for evacuation, and priority of evacuation. Evacuation can be classified as to be evacuate before and after nuclear explosion, and evacuation before nuclear explosion is emergency treatment for survive and evacuation after nuclear explosion is emergency evacuation for the evacuees, which is for the purpose of treatment after damage. Shelters are predesignated and public relations and education are essential for protection.

The concept of dispersion and evacuation should also be developed, and the dispersion for safety of children, pregnant women, and the handicapped or vulnerable people in safety condition, taking into account the time of escape, is very important for minimizing damage. The dispersion means encourage or force residents from areas where a nuclear explosion is expected to occur to evacuate toward safety areas. And evacuation means to be allowed evacuation to be urgently moved toward safety areas as damage is expected. According to case study about survivors of Hiroshima and Nagasaki, the exposure younger age by ten years increases the ERR more than thirty percent and older age by ten years decreases the ERR (Excess Relative Risk) less by ten to fifteen percent $[24,25]$.

\subsection{Establishes and Implements Response, Consequence Management, and Recovery System}

The purpose for establishing of response, consequence management and recovery system is to mitigate and maintain the damage that has occurred, and to maintain earlier national 
function and recover state before damage. Although systematic response activity to mitigate and maintain the damage from nuclear explosions are essential for early consequence management and recover of damage, maintaining of national functions and recovering of state before damage, there are evaluated to have very insufficient response concepts and execution organization in each field.

The response, consequence management and recovery system shall be planning of Time Line to be based on all measures and methods as shown in Figure 6. The joint assessment group consisting of the civilian, government and military forces wearing protective clothing should conduct initial damage assessment and control of the affected areas within thirty minutes of the nuclear explosion through satellite and air, ground inspection, and wind direction analysis. The initial damage assessment and control of joint assessment group consisting of the civilian, government and military forces should be separated into Hot Zone-Warm Zone-Cold Zone to prevent secondary damage and quickly issue response activities guidelines to block spread of damage.

Control of affected areas should be carried out in order from long distance to near distance within one hour after the nuclear explosion. Emergency and rescue activities are partially possible from two hours after the nuclear explosion, site command headquarter by local governments should be established within three hours after the nuclear explosion, and central government integrated command headquarter should be established within four hours after the nuclear explosion.

Rapid decontamination should eliminate secondary damage and anxiety for emergency and rescue workers, support for medical personnel and facilities, and protection measures for relief and recovery workers should also be included. The establishment of an integrated command system and on-site command system are important, and recover of public facilities and emergency repair should be carried out simultaneously with the opening of the street, in order of electronic power, water supply, and communication facilities, or at the same time. Electronic power facilities are essential to prevent secondary damage, water supply facilities are essential for the convenience of the people, and communication facilities are important for the command and control and the maintenance of order of the state.

Since preemptive integrated defense and civil defense posture issues and evacuation to underground evacuation facilities contribute to minimizing post-response, organized and systematic preventive measures are very important in terms of ensuring survival and minimizing damage [21].

\section{Time Line}

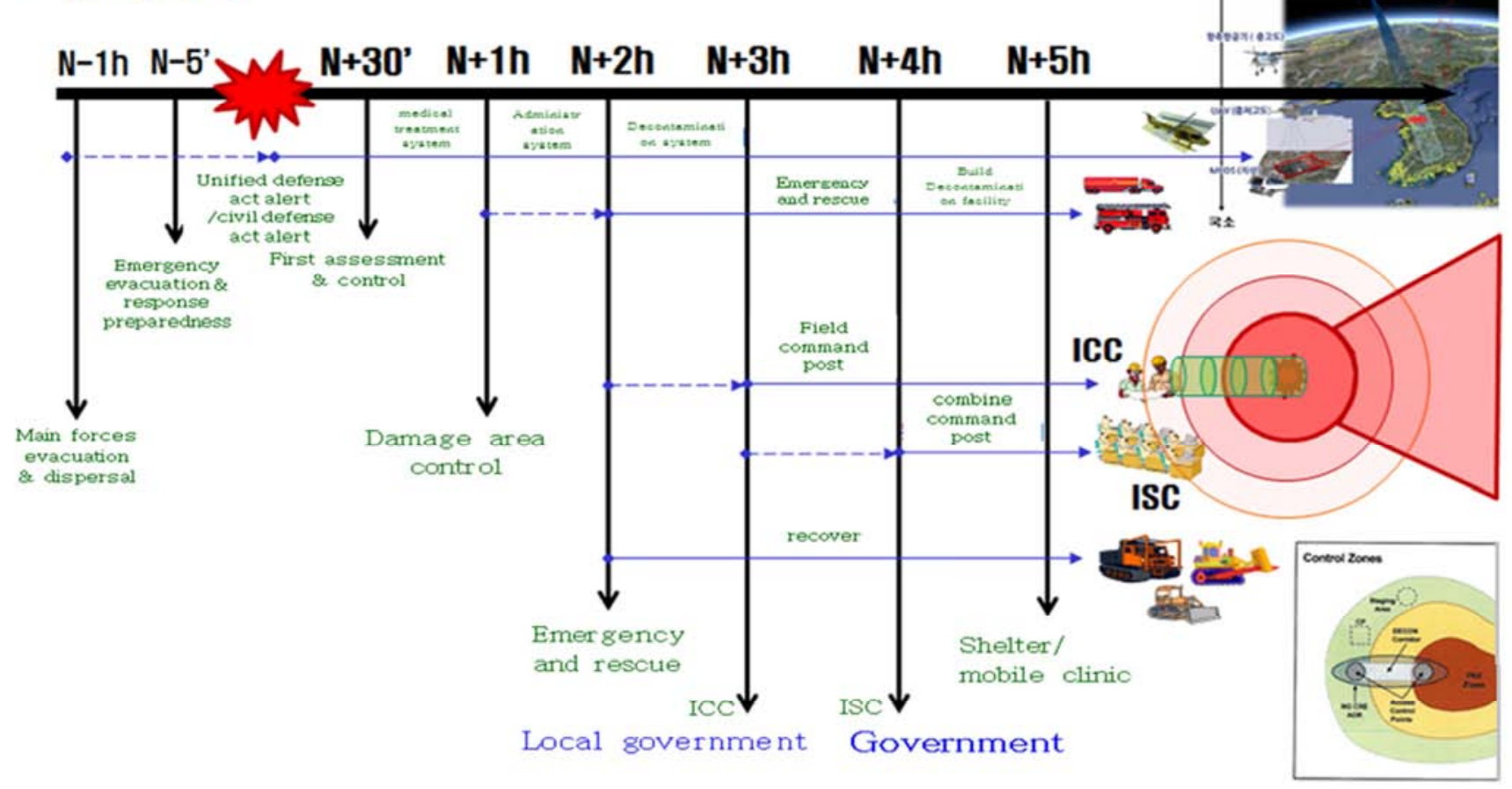

Figure 6. Time Line for Integrated Response of the state after the nuclear explosion.

\subsection{Establishment and Implementation of National Education and Training System}

Understanding the nuclear explosion situation and mastering the basics knowledge and the actions of efficient, effective preparedness and response measures for survival contribute to prevention, mitigation and minimizing of the nuclear explosion damage. Men between the ages of twenty and fourty in Switzerland are required to complete civil defense education (after two to three weeks of general training, basic training and education, function training, special mission training, and re-education courses). The general staff who carry out the civil defense mission will be 
trained within a week and the professional staff and executives will be trained for three weeks (related to disasters and crisis situations).

The education and training system for the people is divided into civilian defense education, national education, and combined training of the civilian, government and military forces. Civil defense education is divided into general and professional education, and national education can be divided into public officials, teachers and students, and others. Public administration offices and public places should distribute and store pamphlets on the Principles of national Action for the entire people so that they can guide the people. The government and local governments should ensure the completeness and adequacy of their preparedness and response capabilities by combining monthly civil air defense training, annual Hwaurang training, Chungmu training, and UFG exercises [21].

\subsection{Establishing and Construction of Telecommunication and Intelligence Distribution System}

Real-time telecommunication and intelligence distribution and unified control of command such as timely alert and warning of the expected damages areas, spread of risk and control areas, and dissemination of response measures improve much more efficiency and effectiveness of preparedness and response. After the damage has occurred, Siren of the Korea Institute of Nuclear Safety (KINS) and NBC RAMS 2.0 of the military need to be combined to provide a supplement to reduce damage when integrated risk prediction programs are disseminated nationwide [21].

The distribution of real-time intelligence and command unification of the public and the military to increase the integrity and effectiveness of the national nuclear defense system is essential and guaranteed. Building an integrated information distribution system so that various information sharing and real-time situations can be displayed will help minimize damage by mitigating and maintaining damage. Linkage of smart ICT capabilities, such as national command and control communication network, system of local government and military force, and communication equipment of general-purpose, will require interoperability and standardization of government, local governments and military, and will enable Live Common Situation Map (COP) distribution. And the unified leadership of the TRS (Trunked Radio System) will enable effective response by allowing control of damage situations, structures and restoration situations. It is also necessary to maintain an emergency communication and satellite communication system in case the communication system becomes paralyzed due to EMP effects.

\section{Conclusion}

At a time when the North Korea's nuclear threat has become a reality and presently situation, sufficient preparedness and readiness to respond to the worst situation is a means to force deterrence. Therefore, we must recognize the importance, need and urgency of applying the Golden Rule early to establish of the national nuclear protection system, a realistic response.

The purpose of nuclear protection is to "make sure of survival and minimize damage and prevent proliferation for victory by overcoming atomic bomb damage and maintaining operational capability in war." The goal of the nuclear protection system is to "be readiness and posture of prepare for survival and response to minimize damage." The nuclear protection objective presented in this study is to reduce the expected damage by at least from ninety percent to fifty percent. Preemptive preparedness will reduce the initial damage (explosion, heat radiation, radiation exposure) of a nuclear explosion by more than fifty percent, prevent fallout damage by more than ninety percent, and minimize the damage through systematic pre-response. This reflects the completeness and willingness of national level of the nuclear protection system.

The Golden Rule of the nuclear protection system to achieve the nuclear protection target level is to make all the preparations in advance and make additional efforts in the shape rather than response. It highlighted the importance of preparedness, such as evacuation facilities and evacuation systems, nuclear crisis management systems, education and training systems, next should be required all of effort for response, and then need a shape for them including the need for legal and institutional supplementation, and communication information management systems. The underground evacuation facility reduces much more the damage from the initial damage and the fallout, while the evacuation system, including dispersion and evacuation, enhances the effect of reducing damage. In addition, supplementation of the national nuclear crisis management system, such as timely alert and warning, evacuation to underground evacuation facilities, and control tower roles, will enhance the effect of reducing damage. In particular, the continuous and repetitive training and education will increase synergy effects and greatly reduce expected and incurred damage. Systematic post-response, such as timely emergency and relief, and fire suppression, will reduce secondary damages by mitigating and preventing the spread of damage, while legal and institutional supplementation and establishment of communication information management system will contribute to minimizing damages.

To this end, it is necessary to implement low-cost nuclear protection measures priority that can be implemented immediately, such as early alert and warning system, education and training for the people. The first priority should be to establish long-term and short-term plans to utilize the military's capabilities and to acquire capabilities in the long-term. Since effective use of the Civilian Defense Force is crucial to minimize damage, the expansion of civilian defense capabilities and restructuring of the structure should be positively considered. Legal and institutional supplementation is essential for this. It also highlights the importance and the need for an international cooperation system to be supported by FCM of the U.S., 
cooperation of the United Nations, and IGO and NGO for supplementation of function and parts beyond government capability.

The Golden Rule presented earlier is based on research that the establishment of preparedness system before nuclear explosion should be built priority than the establishment of response system after nuclear explosion in order to achieve the short-term low-cost, high-efficiency. This is the result of considering the availability, feasibility and practicality. And then it will be necessary developing verification, further deeply development, and detailed result paper through continuous research in the future.

\section{References}

[1] Cresson H. Kearny. (1987). Nuclear War Survival Skills (Oregon: Oregon Institute of Science and Medicine Cave Junction, 1987).

[2] Grace, C. S. (1994). "Nuclear Weapons-Principles, Effects \& Survivability, Brassey's”. UK.

[3] Siegfried S. Hecker. (2015). "The real threat from North Korean is the nuclear arsenal built over the last decase," Bulletin of the Atomic Scientists.

[4] National Institute of Disaster and Safety. (2015a). "Development of Human Resource Allocation Model by Analyzing Spatial Characteristics of Crisis Types in the event of an emergency." pp. 19-20.

[5] National Institute of Disaster and Safety. (2015b). "Standard Framework for National Disaster Management".

[6] National Institute of Disaster and Safety. (2015c). "Improvement of emergency services in disaster situations."

[7] National Institute of Disaster and Safety. (2015d). "The study on the characteristics of evacuation for the weak."

[8] Ministry of Public Safety and Security. (2016a). A Study on the Improvement of the Emergency Safety Network Act.

[9] Ministry of Public Safety and Security. (2016b). "Planning measures to strengthen disaster response capabilities and developing educational content."

[10] Ministry of Public Safety and Security. (2016c). A Study on the Improvement of Residents` Abuse Standards in the Civil Defense.

[11] Park Nam-kyun. (2015). "A Study on the Planning and Design of a Civil Defense Evacuation Facility: Focused on the Factors of Consideration in the Military Threats." The Journal of the Korean Disaster Information Society. the eleventh volume the Korean Association of Disaster Information.

[12] Lee Choon-Geun. Kim Jong Sun. (2016). "The type of damage caused by high-altitude nuclear explosions and protective measures." STEPI Insight." 189. Institute of Science and Technology Policy.

[13] Eunjonghwa. Kim Tae-Hwan. (2013). "A Study on the Conversion of Public Shelters to Fire Protection Facilities in the Civil Defense Commission," said the Korean Association of Disaster Information Society.
[14] Atomic Energy Control Technical Institute 'KINAC/TR-044 Technology Report (2010), p. 5.

[15] Kim Hak-Min. (2015). "The direction of preparedness in response to North Korea's growing nuclear threat: focusing on minimizing damage through defense and follow-up management and maintaining national functions," said South Korea's national security and defense from 2015-2016. Seoul: Korea Institute for Defense Analyses. pp. 255-282.

[16] Japan Foreign Affairs. (2014). "Research Study on Impacts of the use of Naval Nuclear Weapons in Varies Aspects" Commissioned by the Ministry of Japan Foreign Affairs. p. 16.

[17] Kim Hak-Min. (2016b). "Our preparation and response direction: the urgency and necessity for the establishment of a protection and follow-up management system." The National Defense Journal." September issue. pp. 8-11.

[18] John Hersey. (1989). HIROSHIMA. New York: Vintage.

[19] Park Hwi-rak, (2015). We have to live in nuclear war. The 10th stage of common sense of survival 21st Century Military Research Institute, pp. 113-115.

[20] Matthew G. Mc Kinzie \& Thomas Cochran, "Nuclear Use Scenarios on the Korean Peninsula," Natural Resources Defense Council, prepared for the Seminar on International Security Nanjing, China (October 12-15, 2004).

[21] Kim Hak-Min. (2018). "Proposals for the early establishment of the national nuclear defense system." "Defense Policy Study." Volume 34 No.1 pp. 37-70.

[22] Kim Hak-Min. (2016a). "South Korea's preparation and response to North Korea's fourth nuclear test." Volume 32 No.2 pp. 31-61.

[23] Rozdilsky, J. L. (2009). Emergence Management in Israel: Context and Characteristics, Comparative Emergency Management Book Project. FEMA.

[24] Kim Sun-sil. (2013). A Life Cycle Study for the Proliferation Security Initiative Seminar.

[25] Kotaro Ozasa, Yukiko Shimizu, Akihiko Suyama, Fumiyoshi Kasagi, Midori Soda, Eric J. Grant, Ritsu Sakata, Hiromi Sugiyama and Kazunori Kodama. (2012). "Studies of the Mortality of Atomic Bomb Survivors, Report 14, 1950-2003: an overview of cancer and noncancer diseases" (Radiation Research No. 177). Radiation Research Society.

[26] Kim Tae-woo. (2010). "The need for North Korea's nuclear test and strengthening of its extended deterrence," Baek said. "Korea's Security and Defense 2010-2011." Seoul: Korea Institute for Defense Analyses. pp. 161-204.

[27] U.S. Department of Homeland Security. (2012). The National Accident Management System. Lee Eung-young. Busan: Busan University Press.

[28] Song Gun-yong, Kim Young-im, Kim Tae-jung. (1997). A Survey on the Actual Condition of the Victims of the Korean Atomic Bombs.

[29] Brian Green. (1984). "The New Case for Civil Defense." Backgrounder.

[30] Federal Emergency Management Agency. (2014). "Integrated Public Alert and Warning System (IPAWS): Strategic PlanFiscal Year 2014-2018”. DHS. 
[31] Homeland Security National Preparedness Task Force. (2006). "Civil Defense and Homeland Security: A short History of National Preparedness Efforts" Washington D. C.: Department of Homeland Security.

[32] Homeland Security. (2013). Threat and Hazard Identification and Risk Assessment Guide: Comprehensive Preparedness Guide (CPG) Second Edition 201.

[33] Philip J. Dolan. (1972). "Capabilities of Nuclear Weapons (U)" (DNA Effects Manual No 1). Stanford Research Institute.
[34] Kristin Archick. (2006). European Approaches to Homeland Security and Counterterrorism. CRS Report for Congress. CRS.

[35] Victor D. Hyder. (2004). "Decapitation Operations: Criteria for Targeting Enemy Leadership" (monograph, United States Army Command and General Staff College). 